\title{
E-Waste Management Practices of Households in Melaka
}

\author{
Ho Sew Tiep, Tong David Yoon Kin, Elsadig Musa Ahmed, and Lee Chee Teck
}

\begin{abstract}
This study aims to identify current e-waste management practices by households in Melaka. Data were collected from a sample of $\mathbf{3 4 5}$ households in Melaka, Malaysia by means of a self-administered questionnaire survey. Snowball sampling which is part of the non-probability sampling was utilized in this research. The results show that the quantities of electrical and electronic equipment (EEE) in use and the rate of replacements of even functioning EEE are increasing, which in turn increase the generation of e-waste. This study also provides evidence that the level of households' awareness towards e-waste recycling is still low. Thus, the time has come for the introduction of a recycling programme for these potentially harmful waste materials. The findings of this study also lead to implications for the theory-deficient of e-waste recycling literature and several policy recommendations for policy makers to enhance household e-waste recycling response rate.
\end{abstract}

Index Terms-E-Waste management practice, household, recycling, possession, replacement, disposal.

\section{INTRODUCTION}

In Malaysia, based on the study done by Perunding Good Earth Sdn. Bhd [1], it is projected that the amount of discarded used electrical and electronic equipment (EEE) generated will be increasing at an average of $14 \%$ per year and reaching a total of 1.17 billion units or 21.38 million tonnes of e-waste by the year 2020. Television sets and mobile phones contribute to the largest proportion of Waste Electrical and Electronic Equipment (WEEE) in terms of volume. Specifically, the average e-waste generated by households in Malaysia was 700,000 tonnes [1].

Generally, there are two main internal sources of e-waste generation in Malaysia, that is, from households and industries. According to the Department of Environment (DOE) Malaysia, all these e-wastes are classified as scheduled wastes that must be handled by licensed contractors and transported to licensed recycling plant or disposed of in scheduled waste disposal facility [2]. However, the e-wastes collected by the DOE-licensed contractors are mostly from industrial facilities but not from the households even though DOE has the jurisdiction to do so [1]. In other words, the proper procedure is not being complied, especially amongst the households.

Malaysian government is now facing the challenge of dealing with the ever growing e-waste issues. Based on the study by PGE [1], the total weight of WEEE is 688,066 tonnes just for the year 2008, but will be expected to reach 1.119 million tonnes in the year 2020. In response to this challenge,

Manuscript received September 11, 2014; revised January 10, 2015.

Ho Sew Tiep is with Faculty of Information Science and Technology, Multimedia University, Malaysia (e-mail: stho@mmu.edu.my).

Tong David Yoon Kin, Elsadig Musa Ahmed and Lee Chee Teck are with Faculty of Business, Multimedia University, Malaysia. e-waste regulation has been put in place in Malaysia since 2005. With the enforcement of the Environmental Quality (Scheduled Wastes) Regulations, 2005, which was enforced on 15 August, 2005, no one is allowed to dispose e-wastes into landfills. This has been widely practised by the industrial sectors, but it is still an issue at the household level.

Obviously, Malaysia's household e-waste recycling system is still at an early stage [3]. Moreover, those e-wastes generated internally by households are still beyond the control of the authorities. John et al., [4] reveal that only $5 \%$ of the e-waste recycled by the Material Recovery Facilities in Malaysia was collected from households. It is apparent that e-waste recycling effort from households is still very low and the reasons for this are still unclear.

Although there are e-waste recycling programs for households in Malaysia, these programs are given little priority as compared to the systematic and comprehensive e-waste management in the developed countries like Japan, Korea, and UK. The e-waste recycling and disposal is typically disorganized at present. This may be due to the impacts of e-waste which are not immediate unlike municipal solid waste, such as paper, plastic, glass, and etc. that affect our daily life. However, the increase of e-wastes dumping would threaten human health and create environmental issues.

Malaysia consists of 13 states (negeri). Among the states, little is known of Melaka. Located in the southern region of Peninsular Malaysia, Melaka, a popular tourist's state. However, little is know about Melaka e-waste management and recycling. With the recently launching of the government campaign to 'Go Green' vision 2020, conducting a research on Melaka household e-wastes management will suffice this campaign and provides an insight of Melakan understanding of e-waste recycling. Based on this reason, we raise the research question of:

What is the current e-waste management of households in Melaka?

The main objective of this research is to assess the current e-waste management practices of households in Melaka by identifying an average household's EEE (televisions, computers, and mobile phones) possession, replacement and disposal. Through this study a concise overview of Melaka's current e-waste scenario would be gained. In general, it would also help the waste management authorities in Malaysia in their planning of the collection system and facilities needed for effective management of e-waste generated by households in the near future.Generally, there are two main internal sources of e-waste generation in Malaysia, that is, from households and industries. According to the Department of Environment (DOE) Malaysia, all these e-wastes are classified as scheduled wastes that must be handled by licensed contractors and transported to licensed recycling plant or disposed of in scheduled waste disposal facility [2]. 
However, the e-wastes collected by the DOE-licensed contractors are mostly from industrial facilities but not from the households even though DOE has the jurisdiction to do so [1]. In other words, the proper procedure is not being complied, especially amongst the households.

\section{LITERATURE REVIEW}

\section{A. Overview of e-Waste Management}

Solid waste management is a massive task for many countries in the world. However, the penetration of e-waste has made it more complicated. The generation of tremendous amount of bulky WEEE is indeed a source of hazardous wastes. If these e-wastes are not handled properly, they cause not only a huge number of waste waiting for disposal, but also pose a severe adverse impact on the environment and human health due to their complex components with toxic and hazardous substances such as lead, beryllium, mercury, cadmium, and brominated flame retardants and many others [5]-[7]. All of these toxic substances jeopardize our rivers and lakes, our air, land and oceans, and eventually our future. Hence, there exists a pressing need for the environmentally sound management (ESM) of e-waste. Detailed assessment of e-waste inventory, disposal practices, e-waste collection, and etc. should be established and involved all stakeholders. This proper e-waste management program should also comprise of the $3 \mathrm{Rs}$ - reduce, reuse and recycle. Most importantly, a strong enforcement is essential, else the public would just neglect them.

\section{B. E-Waste Management in Malaysia}

In Malaysia, e-wastes are commonly defined as 'used' electrical and electronic assemblies categorized as scheduled wastes in the First Schedule of the Environmental Quality (Schedule Wastes) Regulations 2005, administrated by the Department of Environment [8]. There is no definition, specifically for e-waste in Malaysian domestic regulation. Under code SW 110, e-wastes are defined as waste from the assembly of electrical or electronic appliances that consist of components such as accumulators, mercury-switches, glass from cathode-ray tubes and other activated glass or polychlorinated biphenyl-capacitors, or contaminated with cadmium, mercury, lead, nickel, chromium, copper, lithium, silver, manganese or polychlorinated biphenyl [8]. Generally, in layman terms, e-wastes embrace a broad range of electrical and electronic devices that have been discarded from as big as a refrigerator to as small as a calculator.

In response to the flood of imported e-waste, on 5 May 1992, Malaysia has ratified the Basel Convention, a global agreement regulating movement of hazardous wastes which targets to safeguard human health and the environment from the adverse impacts of toxic waste. Malaysia is one of the 166 parties to the convention (as of Nov, 2005). In addition, the Royal Malaysian Customs (RMC) is responsible for managing the transboundary movements of hazardous waste under the Customs Act, 1967, specifically, the Custom (prohibition of Import) Order 2008 and the Customes (Prohibition of Export) Order 2008 [1]. Through the prohibition of imports and exports of waste, RMC is able to prevent any illegal trafficking of hazardous waste, such as e-waste.

On the other hand, in order to manage internal sources of e-waste generation, there is a procedure in place by DOE. According to the procedures, licensed contractors are required to transport and deliver all these e-wastes (classified as the scheduled wastes) to licensed recycling plant or disposed off in the centralised scheduled waste treatment and disposal facility in Bukit Nanas, Negeri Sembilan [2]. At present, the licensed contractors are located in various part of the country, with 96 partial recovery contractors and 11 full recovery contractors. Their sources of e-wastes are from several middleman, collectors and recycling centres. The main activities are to recycle normal recyclable materials such as plastics and metals and also to extract valuable metals such as gold, platinum, silver and lead from the circuit boards.

\section{E-Waste Initiatives in Malaysia}

The DOE who is the e-waste administrator in Malaysia has established a collection and recycling system for household e-waste. As for a start, the public can send their e-wastes, limited to used mobile phones, mobile phone's batteries and their accessories, computers and their accessories, as well as television sets to the e-waste collection centres with the addresses posted in the DOE's website (http://www.doe.gov.my). The solid waste concessionaires/local authorities are responsible for managing these e-waste collection centres.

Besides, a project on International Recycling Networks for Mobile Phones in Asian Region which was conducted by E\&E Solution Inc. from November 2006 to March 2007 funded by DOWA Eco-system Co., Ltd., with the support from Ministry of Environment in Japan, and cooperation with PCD in Thailand, DOE in Malaysia and NEA in Singapore, had already been carried out. One of the objectives of the project is to establish transboundary movement schemes of used mobile phones generated in these countries to Kosaka Smelting and Refining Co., Ltd located in Japan in order to ensure the recycling of e-waste in environmentally sound manner. However, it is doubtful that the general public is aware of this program.

On the other hand, a substantial amount of EEE producers in Malaysia have also initiated a small scale Take Back Program (TBP) to reduce the number of WEEE from being discarded to landfills. In fact, this TBP for proper disposing of e-waste is urged by the Ministry of Natural Resources and Environment (MNRE) and some of the programs have already been started by some major EEE manufacturers like Panasonic Malaysia, Motorola (M) Sdn. Bhd, Nokia Malaysia, Dell Malaysia, and HP-Compaq [1]. However, these programs and facilities are found insufficiently reaching the public and their effectiveness remains elusive. This can be seen as a matter of fact that many people are still storing their e-waste at home. It is believed that a major concern about the take back program in Malaysia is the availability and accessibility of such programs. Generally, the public is not well informed of such program by the companies and they are usually restricted to certain areas only. Hence, members of the public who intend to participate in the program may be hindered due to a lack of information and inconvenience. 
Lately, FOMCA (Federation of Malaysian Consumers Association) starts to show great concern about e-waste issue in Malaysia and various related topics are published such as $3 \mathrm{R}$ practices, eco-label, green advertising and marketing in its monthly consumers' bulletin in order to educate and raise awareness among the Malaysian. Similarly, Tzu Chi, a charity Organization has also been involved actively for many years in household recycling and recently it has also started the collection centre for e-waste. According to the person in charge, H.C.Yew (personal communication, October 20, 2010), those e-wastes will be collected by some scrap companies and to be sold as second hand products if they are still workable or to be recycled. However, the actual measures taken are unclear and also the response from the public towards e-waste recycling remains generally unsatisfactory.

In a nutshell, some efforts to enhance e-waste recycling among Malaysian have been made but mostly on an ad hoc basis by local authorities or nongovernmental organizations (NGOs). The e-waste recycling and disposal is typically disorganized at present. Therefore, a well set up e-waste recycling scheme which is informed by an understanding of the situation and driven by public's needs is extremely crucial in steering the public towards effective e-waste recycling.

\section{ReSEARCH Methodology}

This study is based on a questionnaire survey that consists of quantitative approaches for data analyses. Some secondary data and views from the expert have been analysed. This sets the direction for an effective questionnaire design before distribution, by snowball sampling to households in Melaka state. The target population [9] are households who have the luxury to own mobile phones, televisions, and computers and they could probably form the largest group that generate the e-wastes.

In this study, individual within a household is the unit of analysis. Hence, the survey was conducted among Melaka households (one individual per household) aged 21 years and above, who typically have high disposable income and the willingness to spend money on EEE. It was expected that the selection of one individual per household would produce better representativeness of the sample [10] and also to avoid redundant information collected. To ensure this, while distributing questionnaires, participants were informed about the criteria of one individual per household verbally.

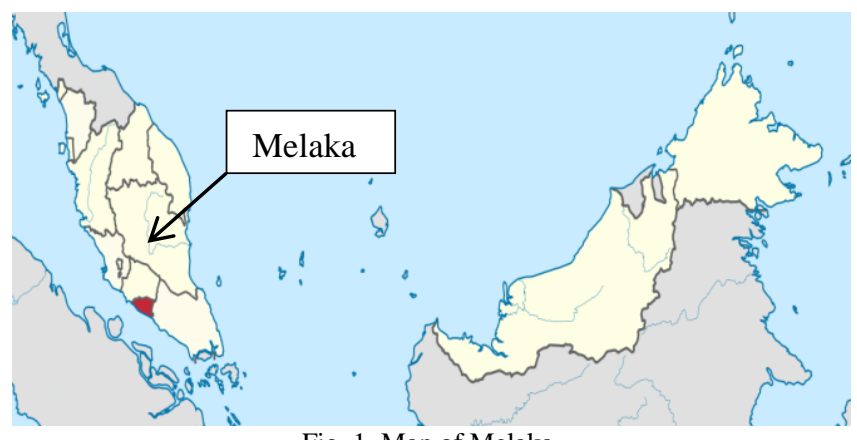

Fig. 1. Map of Melaka.

This study was conducted in Melaka, the third smallest state of Malaysia which is situated in the southern part of the
Peninsular Malaysia, next to the Straits of Melaka (refer to Fig. 1). Melaka City is the capital, and since 7 July 2008, this historical city centre has been recorded as a UNESCO World Heritage Site. Melaka was selected for the research both on research and logistic grounds. The researchers are based in Melaka, providing easy access and to build on research into e-waste management in Melaka. In addition, this is also in line with the Melaka government's 'Go Green' vision 2020.

In this study, the first section of the questionnaire gathers the data for the distribution of participants' information. The second section collects the information about participants' possession as well as, frequency of replacement and disposal of EEE. Specifically, participants were asked to state the number of the particular categories of electronic items (televisions, computers, and mobile phones) disposed during the past five years and the number of unit(s) which they possessed (both still in use and not use). Furthermore, participants were prompted on their frequency of replacing these specific classifications of electronic items. This was followed by asking them about their methods of disposal. Lastly, the reasons for the disposal of these obsolete EEE were asked.

There are three types of EEE targeted in this survey which are televisions (TVs), computers (PCs) and mobile phones (MPs). Together, these e-wastes will pose one of the major threats to pollution if mismanaged. Continual incremental technology innovation has shortened the product life span of these products. For example, the CRTs have been replaced by LCD flat screen TV with highly competitive prices. This means when these products are faulty, consumers will no longer eye for repair but replace them instead. According to Andreola et al., [11], TV sets and computer monitors containing CRTs represent around $80 \%$ of the total e-waste in the European Union (EU). For Malaysia, in the future projection of discarded EEE, mobile phones and their rechargeable batteries are projected to be the largest contributor for the overall e-waste generation compared to other e-wastes [1].

\section{RESULTS}

Table I presents a summary of the participants' demographics. The data collected were predominantly female (64.9\%) and Chinese (56.5\%). The age group with the highest number of participants is the 31-40 age with 106 participants. For education levels, the percentage of graduate and non-graduate are $47 \%$ and $53 \%$ respectively. As for the participants' remuneration details, most of the participants are paid between RM2500 to RM6999 (51.6\%).

\begin{tabular}{|c|c|c|}
\hline & Demographic Profile & $\%$ \\
\hline Gender & $\begin{array}{l}\text { Male } \\
\text { Female }\end{array}$ & $\begin{array}{l}35.1 \\
64.9\end{array}$ \\
\hline Age & $\begin{array}{l}21 \text { to } 30 \\
31 \text { to } 40 \\
41 \text { to } 50 \\
51 \text { and above }\end{array}$ & $\begin{array}{l}26.1 \\
30.7 \\
23.2 \\
20.0\end{array}$ \\
\hline Ethnic & $\begin{array}{l}\text { Malay } \\
\text { Chinese } \\
\text { Indian } \\
\text { Others }\end{array}$ & $\begin{array}{c}35.9 \\
56.5 \\
6.4 \\
1.2\end{array}$ \\
\hline
\end{tabular}




\begin{tabular}{|ll|c|}
\hline \multicolumn{2}{|c|}{ Demographic Profile } & \% \\
\hline Gender & Male & 35.1 \\
& Female & 64.9 \\
\hline Education Level & SPM/SPVM/MCE/O Level & 33.0 \\
& STPM/Diploma/A Level & 17.7 \\
& Degree & 32.5 \\
& Master & 14.2 \\
& PhD & 0.3 \\
& Others & 2.3 \\
\hline Household Gross & Less than RM 2500 & 36.0 \\
Monthly Income & RM 2500 to RM 6999 & 51.6 \\
& RM 7000 and above & 12.4 \\
\hline Total (\%) & & 100 \\
Total number of respondents & 345 \\
\hline
\end{tabular}

\section{DISCUSSION}

\section{A. Disposal and Possession of TVs/PCs/MPs by the Participants}

Once a household has used the EEE until its end of life, the equipment will undergo the mechanism of disposal. An analysis of the amount of EEE disposed during the past five years for household (refer to Fig. 2), showed that mobile phones disposal has the highest average of 1.71 per household, followed by 0.78 for personal computers, and 0.75 for televisions. Most of these waste electrical and electronic equipment (WEEE) are believed to end up in the landfill sites without proper treatment as there is no adequate segregation or disposal system to convince the Malaysian to recycle and discard e-waste presently [3]. This can be reflected from the scenario that some companies struggle to get enough old mobile phones to feed the recycling plants [12].

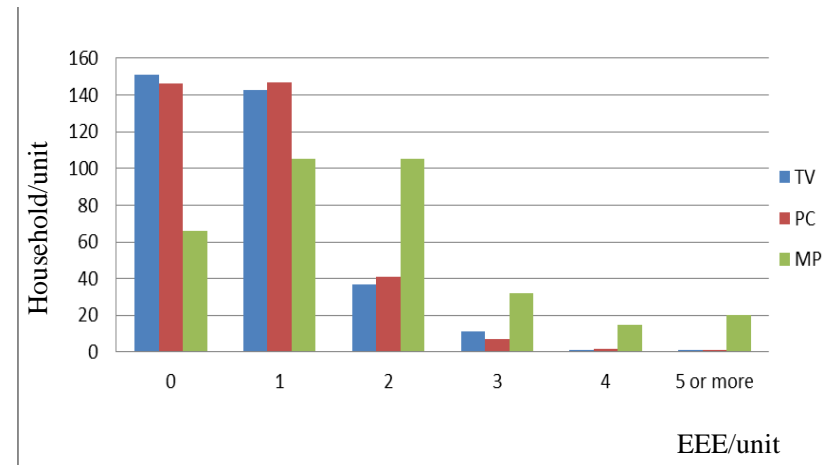

Fig. 2. Amount of TVs/PCs/MPs disposed during the past five years by the participants.

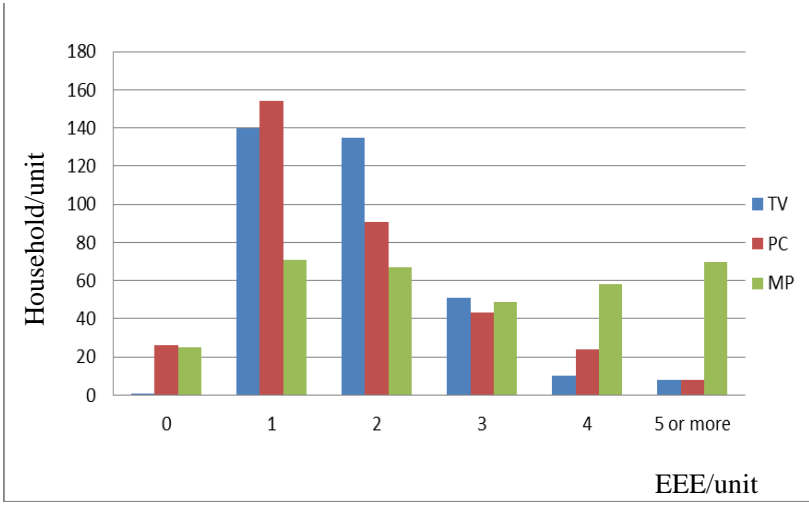

Fig. 3. Amount of TVs/PCs/MPs owned in house by the participants.

Similarly, the study by PGE [1], found that mobile phones contributed the most to the total e-waste generation compared to other e-wastes. For TVs and PCs, the figures are relatively low compared to mobile phones mainly because these are used for much longer. Comparing PCs and TVs, even though the replacement rate for PCs is high nowadays, the rate of penetration for computers is slower than TVs as PCs were introduced much later compared to TVs. Hence, take-up rate for PCs has been slower in comparison. However, it is likely that this trend will transform with the ongoing government initiative to multiply the ownership of PCs. Besides, the penetration of tablets which are heavily marketed by giant companies like Apple and Samsung may also contribute to the rapid face out of the $\mathrm{PCs}$.

Rapid technological development in EEE industries offers a wide range of product choices besides more affordable prices. Hence, the EEE usage has become more and more popular. Besides, this also gives individuals the opportunity to have EEE at home. From the data compiled in Fig. 3, it was found that the average possession of televisions, personal computers, and mobile phones are 1.86, 1.75, and 3.1 respectively for each household. This indicates that households can own not only one type of EEE, but several units of the same type of EEE, with mobile phones at the top of the list. This also shows that IT and telecommunication and computer networking products have penetrated nearly every aspect of modern life. EEEs which were considered as luxury items in the early stage of Malaysia's economic development have now become necessities and are affordable to all households. In short, the heavy reliance on these equipment nowadays will definitely contribute to the growth of electronics items in the waste stream.

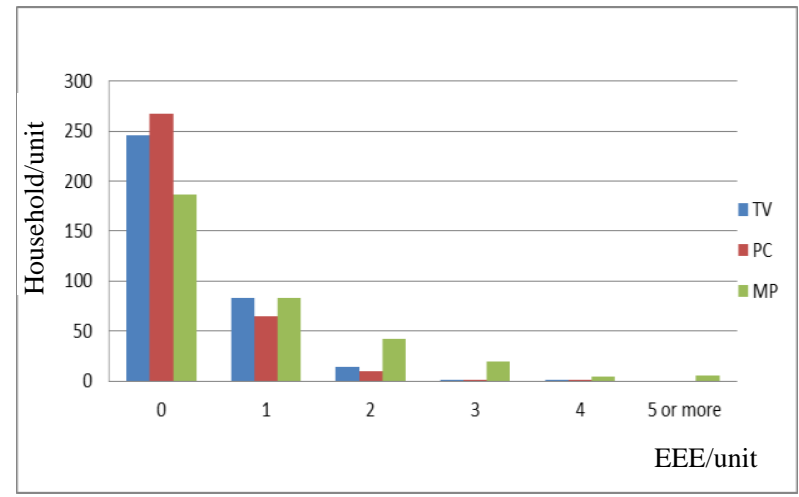

Fig. 4. Amount of TVs/PCs/MPs owned in house (but not use) by the participants.

For the average unwanted EEE that are still in possession by the participants, it has an average of 0.34 for televisions, 0.27 for personal computers, and 0.78 for mobile phones (refer to Fig. 4). Again, mobile phone is leading the list. Even though these numbers are likely lower bounds, it does indicate that many households have accumulated e-waste. It also indicates that there is an increasing pile of used and obsolete EEE which can readily to enter the municipal waste stream. This result obtained is similar (except mobile phones) to the study of PGE [1] where it was found that the percentage of unwanted EEE presently owned by households is $23.95 \%$. A study by Nokia indicated that many used phones are kept in houses of users [13]. This also indicates that many participants do not immediately dispose of or recycle EEE that are no longer in use. Some possible factors that add to the 
hoarding of unwanted EEE are:

1) Households do not know how to dispose of it safely and conveniently.

2) Households may think that some of the internal component of the equipment can still be used and thus are kept for future cannibalization of parts.

3) Households face reluctance in disposing their WEEE as they had spent a great deal of money to purchase these items.

4) Households are waiting for collectors to purchase the discarded WEEE from them.

The fate of these used EEEs which are still possessed by participants should be given great concern because if they are improperly disposed, they may be harmful to human health and the environment due to their toxicity and growing volume.

\section{B. Replacement of TVs/PCs/MPs by the Participants}

Based on Fig. 5 and Table II, mobile phones had the fastest replacement turnover of all the three categories tested, where $28.7 \%$ of the participants claimed that they replaced their MPs in less than 2 years and about half, i.e. $47.3 \%$ of the participants replaced their mobile phones between two to five years. Moreover, a minority or equivalence to $0.6 \%$ participants even changed into new ones within 6 months. This finding is quite compatible with the study done by E\&E [13] where the frequency of changing mobile phones is once per 12-18 months an average. This scenario reflected that the advancement of mobile telecommunication results in a high frequency of changing mobile phones because consumers are attracted by their features and stylistic expectations such as coloured screen, audio quality, bigger memory capacity, etc. According to Huang et al., [6], the main reason for upgrading EEE is the commencing of up-to-date products with more advanced features. This can be seen from the launching of iPhone 4, where people were willing to wait and queue in a long line extending all the way back from the entrance of the sales site just to own the latest smartphone [14]. In other words, the rapid replacement of old models by the latest advanced model periodically indeed leads to the short average lifespan of EEE. According to E\&E [13], mobile phones usage have increased tremendously in Malaysia, with around 17 million mobile phones that have been used, and a diffusion rate of $70 \%$ (whole country), and $100 \%$ in urban areas. Consequently, with the high replacement rate as observed in the study, increasing quantities of waste in the form of mobile phones are expected to be generated in the country.

In terms of TVs and PCs, a majority (74 percent) of participants claimed to keep their television for at least five years before replacing it, and only about $46.9 \%$ of participants did so for PCs (refer to Table II). This showed that the participants tended to keep their TVs much longer than PCs. The reason might be because the technology upgration of TVs is not as fast as PCs. However, with the more competitive price of plasma TV, LCD TV or LED TV, the conventional CRT TV will soon be faced out due to the affordability of the new products. Besides, the replacement of PCs might also continue to grow due to the government's call for citizens to be more IT savvy. Hence, the increased usage of these EEE in our daily life will result in e-waste generation.

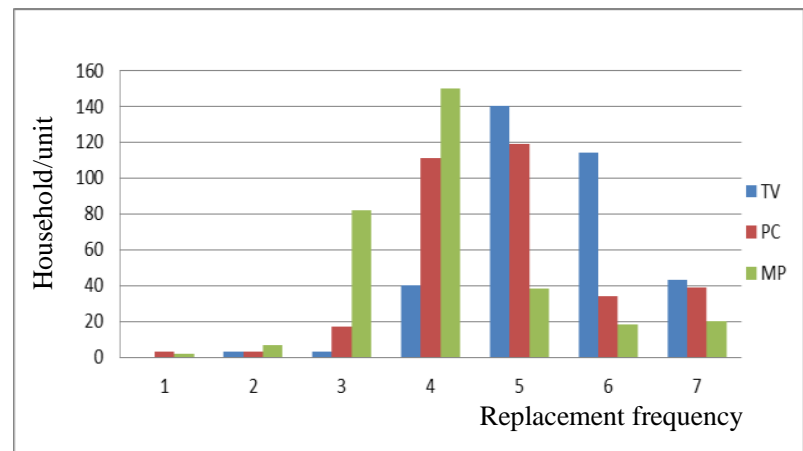

Fig. 5. Replacement of TVs/PCs/MPs by the participants.

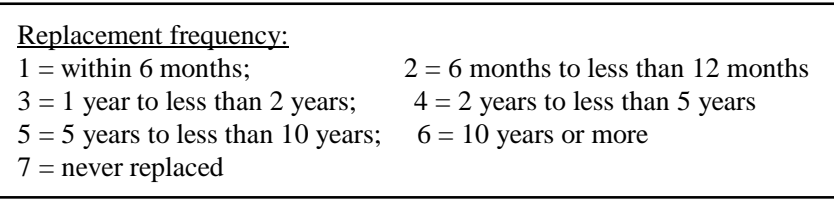

TABLE II: REPLACEMENT OF TVS/PCS/MPS BY THE PARTICIPANTS (BY PERCENTAGE)

\begin{tabular}{llccc}
\hline & Option & TVs & PCs & MPs \\
\hline 1 & within 6 months & - & 0.9 & 0.6 \\
2 & 6 months to less than 12 months & 0.9 & 0.9 & 2.2 \\
3 & 1 year to less than 2 years & 0.9 & 5.2 & 25.9 \\
4 & 2 years to less than 5 years & 11.7 & 34.1 & 47.3 \\
5 & 5 years to less than 10 years & 40.8 & 36.5 & 12.0 \\
6 & 10 years or more & 33.2 & 10.4 & 5.7 \\
7 & never replaced & 12.5 & 12.0 & 6.3 \\
\hline
\end{tabular}

\section{TVs/PCs/MPs Disposal Practices by the Participants}

From a detail analysis on Fig. 6 and Table III, the highest disposal method for TVs and PCs is 'gave to friends or relatives', and 'traded in' is the most popular disposal method for MPs. Those who gave their TVs and PCs to friends or relatives made up a percentage of $30.6 \%$ and $19.7 \%$ respectively. It can be inferred that a certain percentage of such equipment is actually still in good condition. As 'traded in' for MPs made up a percentage of $28.7 \%$, this indicates that it is widely accepted by teleshops due to a demand for second hand MPs. Both these two methods can extend the life cycle of EEE and by reusing the equipment, the amount of e-waste can be reduced and at the same time the movement of e-waste into landfills can be delayed.

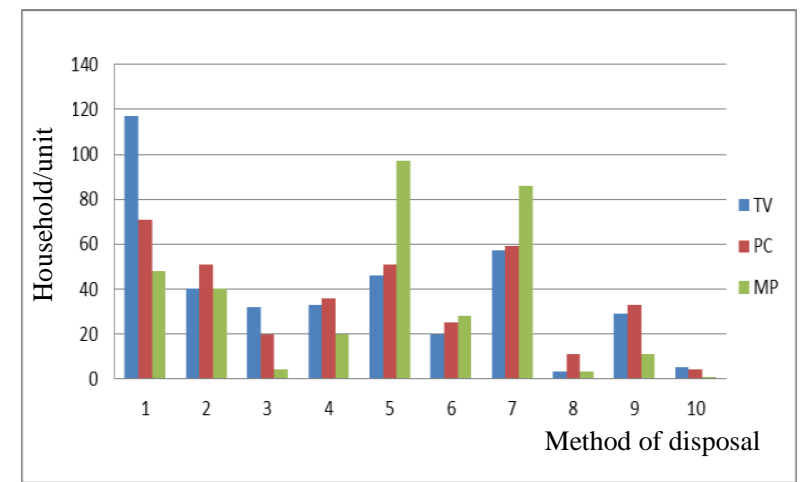

Fig. 6. TVs/PCs/MPs disposal practices by the participants.

\begin{tabular}{ll} 
Method of disposal: & \\
\hline $1=$ Gave to friends or relatives; $\quad 2=$ Sold as second hand equipments \\
$3=$ Donated to charity/school or similar; $4=$ Sent to recycling center \\
$5=$ Traded in; & $6=$ Throw away \\
$7=$ Stored it $/$ kept it no longer in use $;$ & $8=$ Disassembled to reuse \\
$9=$ Gave to scrap collector; & $10=$ Other options
\end{tabular}


The second preferred disposal method of these three types of e-waste disposal is 'stored it/keep it no longer in use', with $14.9 \%$ (TVs), $16.3 \%$ (PCs), and 25.4\% (MPs) respectively. The fact that storage method is chosen rather than reuse or other disposal methods is a crucial factor. This indicates the lack of awareness on where to dispose of obsolete EEE and psychological factors such as the belief that e-waste has some value. On the other hand, the literature has also shown that most consumers keep their unused or broken EEE for years before reselling or disposing of the equipment [1], [15].

However, the vital e-waste disposal method, recycling, did not seem to be popular amongst participants, where $10 \%$ or less of the participants claimed to practice this method for all the three EEE. This showed that merely a very small portion of e-waste ends up in recycling facilities as no well-organized take-back scheme for consumers is in place. In fact, e-waste derived from individual households is not commonly collected, compared to e-waste generated from industries which is in accordance with EQSWR 2005 [4].

\section{Reasons for TVs/PCs/MPs Disposal}

From the data compiled in Fig. 7 and Table IV, the main reason for TVs disposal is 'high repair cost' which had a percentage of $38.7 \%$. This implied that participants rarely sent broken TVs for repair works as it is often easier and cheaper to buy new products than repair old ones. The next reason for TVs disposal is because of its malfunction during use, followed by the fact that its lifespan has elapsed at $21 \%$ and $17.7 \%$ respectively.

As for PCs disposal, the top two reasons are 'high repair cost' and 'outdated' which contributed to $27.7 \%$ and $26.3 \%$ respectively. The first reason could be similar to TVs as mentioned above. For the second reason, it may imply that actually the PCs are retired early even though they are still in good working condition. This might be propelled by the desire to update the latest software or other functionality. Furthermore, it is often less costly and more practical to buy a new PC to have access to a newer generation of technology than it is to upgrade an outdated PC.

As for MPs, about one third of the participants claimed that 'outdated' is the dominant factor for MPs disposal. Similarly, this implies that MPs are often discarded although they still worked perfectly due to new products offer more advanced features or have more trendy designs. Moreover, $19.5 \%$ of the participants claimed that 'high repair cost' drove them to dispose the MP. In other words, they prefer to purchase new products rather than repair old ones. This scenario also reflects the increase in affordability of new products amongst participants.

TABLE III: TVs/PCs/MPs Disposal PRACTICES by tHE PARTICIPANTS (BY Percentage)

\begin{tabular}{clccc}
\hline & Option & TVs & PCs & MPs \\
\hline 1 & Gave to friends or relatives & 30.6 & 19.7 & 14.2 \\
2 & Sold as second hand equipments & 10.5 & 14.1 & 11.8 \\
3 & Donated to charity/school or similar & 8.4 & 5.5 & 1.2 \\
4 & Sent to recycling center & 8.6 & 10.0 & 5.9 \\
5 & Traded in & 12.1 & 14.1 & 28.7 \\
6 & Throw away & 5.2 & 6.9 & 8.3 \\
7 & Stored it / kept it no longer in use & 14.9 & 16.3 & 25.4 \\
8 & Disassembled to reuse & 0.8 & 3.1 & 0.9 \\
9 & Gave to scrap collector & 7.6 & 9.2 & 3.3 \\
10 & Other options & 1.3 & 1.1 & 0.3 \\
\hline
\end{tabular}

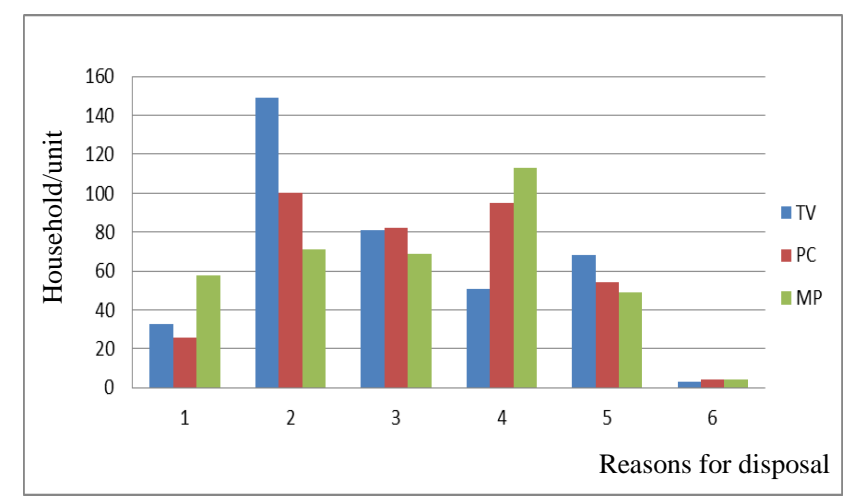

Fig. 7. Reasons for TVs/PCs/MPs disposal

\begin{tabular}{|ll|}
\hline Reasons for disposal: & \\
\hline $1=$ New products are cheap $;$ & $2=$ High repair cost \\
$3=$ Malfunction during use $;$ & $4=$ Outdated \\
5 = Lifespan elapsed; & $6=$ Other reasons \\
\hline
\end{tabular}

TABLE IV: REASONS FOR TVs/PCS/MPs DisPOSAL (BY PERCENTAGE)

\begin{tabular}{llccc}
\hline & Option & TVs & PCs & MPs \\
\hline 1 & New products are cheap & 8.6 & 7.2 & 15.9 \\
2 & High repair cost & 38.7 & 27.7 & 19.5 \\
3 & Malfunction during use & 21.0 & 22.7 & 19.0 \\
4 & Outdated & 13.2 & 26.3 & 31.0 \\
5 & Lifespan elapsed & 17.7 & 15.0 & 13.5 \\
6 & Other reasons & 0.8 & 1.1 & 1.1 \\
\hline
\end{tabular}

\section{CONCLUSION}

This research investigates the e-waste management practices in Melaka. It has successfully gathered information to establish a database needed to tackle the needs and to find answers for the environmentally sound strategy of managing e-waste. From the finding, it was shown that households with increasing purchasing power are able to own several units of the same type of EEE. Besides that, it was found that many households have stockpiled e-waste. Furthermore, the replacement turnover of EEE among household is also found to be fast. These findings imply that there is an ever-expanding pile of e-waste ready to enter the municipal waste stream. Thus, there is a pressing need for the local government to implement immediate measures to handle this crucial e-waste problem.

Furthermore, the results show that e-waste recycling was not popular among Melaka householders. EEE items were put aside even though they are still functional. This provides evidence that the level of households' awareness on e-waste management is still low. In addition, high storage of e-waste indicates lack of awareness on where to dispose of such wastes. We suspect that some households stored them as they belief that e-waste has some values for future recycling.

The absence of regulations and guidelines has posed a serious problem that hindered the success of potential recycling programmes in Malaysia [16]. Currently, there is still no e-waste regulations implemented in Malaysia to cater for local needs and most importantly one that is acceptable by Malaysians. Thus, the local government should table issue and legalise policies, acts, rules and regulations on e-waste management.

In light of the findings, we proposed some recommendations to improve the situations. In the short run, it is essential to handle the stockpile of e-wastes by establishing 
the recycling infrastructure and publicizing information on e-waste recycling or campaigning to enhance the level of awareness of this recycling. In the long run, there should be laws governing recycling of electronic products for householders and EEE producers should contribute to ways of recycling their items.

Overall, this study of e-waste management in Melaka has brought to the limelight on the importance of e-waste recycling. The recycling of e-waste should neither be taken for granted by the publics nor by the EEE producers. The innovation and production of EEE products are expeditious. This has rendered average households to change their gadgets they owned within two to three years. When this situation is beyond control, we build enormous EEE pileups which would have an adverse effect on us and mother earth. We belief EEE producers and the government should play significant roles to recycling these products. Lastly, the cooperation and adoption of e-waste recycling habits by each household will contribute to reducing these effects.

\section{REFERENCES}

[1] Perunding Good Earth (PGE), "The e-waste inventory project in Malaysia," Department of Environment, Malaysia \& EX- Corporation, Japan, 2009.

[2] L. C. Teng, "E-waste management," Impak, issue 1, p. 12, 2008

[3] J. A. Kalana, "Electrical and electronic waste management practice by households in Shah Alam, Selangor, Malaysia," International Journal of Environmental Sciences, vol. 1, no. 2, pp. 132-144, 2010.

[4] B. C. John, S. Chamhuri, F. M. Ahmaz, and A. B. Rawshan, "Bridging the gaps: An e-waste management and recycling assessment of material recycling facilities in Selangor and Penang," International Journal of Environmental Sciences, vol. 1, no. 3, pp. 383-391, 2010.

[5] B. R. Babu, A. K. Parade, and C. A. Basha, "Electrical and electronic waste: a global environmental problem," Waste Management and Research, vol. 25, pp. 307-318, 2007.

[6] P. Huang, X. Zhang, and X. Deng, "Survey and analysis of public environmental awareness and performance in Ningbo, China: A case study on household electrical and electronic equipment," Journal of Cleaner Production, vol. 14, pp. 1635-1643, 2006.

[7] V. Pinto, "E-waste hazard: The impending challenge," Indian Journal of Occupational and Environmental Medicine, vol. 65, 2008.

[8] Department of Environment (DOE), Guidelines for the Classification of Used Electronic and Electrical Equipment in Malaysia, 1st ed. Malaysia, 2008.

[9] A. Veal, Business Research Methods: A Managerial Approach, 2nd ed. Australia: Pearson Education, 2005.

[10] V. O. Valle, E. Rebelo, E. Reis, and J. Menezes, "Combining behavioral theories to predict recycling involvement," Environment and Behaviour, vol. 37, no. 3, pp. 364-396, 2005.

[11] F. Andreala, L. Barbieri, A. Corradi, I. Lancellotti, R. Falcone, and S. Hreglich, "Class-ceramics obtained by the recycling end of life cathode ray tubes glass," Waste Management, vol. 25, pp. 183-189, 2005.

[12] M. Yoshikawa, "GoldMine of metal. The star newspaper," Environment, T7, 2008, June 17.

[13] E\&E Solutions Inc., International Recycling Networks for Mobile Phones in Asian Region, DOWA Eco-system Co., Ltd, July, 2007.

[14] J. X. Chong and S. Subashini. (September 25, 2010). iPhone 4 Comes calling in Malaysia. [Online]. Available: http://thestar.com.my/news/story.asp?file=/2010/9/25/nation/710024 $9 \& \sec =$ nation

[15] J. D. M. Saphores, H. Nixon, O. A. Ogunseitan, and A. A. Shapiro, "How much e-waste is there in US basements and Attics? Results from a national survey," Journal of Environmental Management, vol. 90, pp. 3322-3331, 2009.

[16] M. N. Hassan, T. L. Chong, M. Rahman, M. N. Salleh, Z. Zakaria, and M. Awang, "Solid waste management in southeast Asian countries with special attention to Malaysia," in Proc. Eighth International Waste Management and Lanfill Symposium, Italy: CISA, Environmental Sanitary Engineering Centre, 2001.

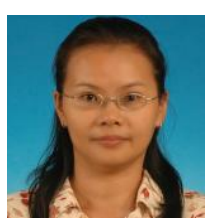

Ho Sew Tiep obtained her bachelor degree from Universiti Technologi Malaysia in 1995 and master degree from Multimedia University Malaysia (MMU) in 2013. Currently, she is lecturing in the Faculty of Information Science and Technology, MMU. Her research is centered on e-waste management. She has published some conference papers and journal papers on household e-waste recycling intention and effective management of e-waste. 